\title{
Green synthesis of silver nanoparticles using Omani pomegranate peel extract and two polyphenolic natural products: characterization and comparison of their antioxidant, antibacterial, and cytotoxic activities
}

Pasent Gharib Saad ${ }^{1}$, Rohan Daniel Castelino ${ }^{1}$, Vimal Ravi ${ }^{1}$, Issa Sulaiman Al-Amri ${ }^{2}$ and Shah Alam Khan ${ }^{1 *}$ (D)

\begin{abstract}
Background: Green synthesis of silver nanoparticles (AgNPs) has gained popularity due to the economical and eco-friendly approach associated with it. The aim of the study was to biosynthesize silver nanoparticles using pomegranate peel extract (PPE), quercetin (Q), and gallic acid (GA) and to evaluate their antioxidant, antimicrobial, and cytotoxic activities.

Results: A sharp color change from yellow to brown, appearance of a peak in a UV spectrum around 413-425 nm, and four intense peaks in XRD spectra matching with the reference silver crystal confirmed the formation of AgNPs. SEM and TEM analysis revealed particles to be mostly spherical with few aggregates. Average particle size distribution and zeta potential was found to be $43.6 \mathrm{~nm}$ and $-18.01 \mathrm{mV}, 31.6 \mathrm{~nm}$ and $-21.5 \mathrm{mV}$, and $21.7 \mathrm{~nm}$ and $-27.9 \mathrm{mV}$ for Q-AgNPs, P-AgNPs, and GA-AgNPs, respectively. P-AgNPs showed excellent in vitro antioxidant activity (84.85-89.20\%) and cytotoxic activity (100\% mortality). P-AgNPs and GA-AgNPs exhibited good antimicrobial activity against the four bacterial strains comparable to the reference antibiotics but Q-AgNPs failed to inhibit the growth of $P$. vulgaris.

Conclusions: Omani pomegranate peel extract seems to be a potential and alternative source for the simple, one pot, eco-friendly green synthesis of extracellular stable AgNPs. The synthesized nanoparticles have the potential to be developed as possible antimicrobial agents and antioxidants.
\end{abstract}

Keywords: Green synthesis, Silver nanoparticles, Antioxidant, Cytotoxic, $\mathrm{AgNO}_{3}$

\footnotetext{
*Correspondence: shahalam@nu.edu.om; sakhan@omc.edu.om

${ }^{1}$ College of Pharmacy, National University of Science and Technology, PO

Box no 620, PC 130 Muscat, Sultanate of Oman

Full list of author information is available at the end of the article
}

(c) The Author(s). 2021 Open Access This article is licensed under a Creative Commons Attribution 4.0 International License, which permits use, sharing, adaptation, distribution and reproduction in any medium or format, as long as you give appropriate credit to the original author(s) and the source, provide a link to the Creative Commons licence, and indicate if changes were made. The images or other third party material in this article are included in the article's Creative Commons licence, unless indicated otherwise in a credit line to the material. If material is not included in the article's Creative Commons licence and your intended use is not permitted by statutory regulation or exceeds the permitted use, you will need to obtain permission directly from the copyright holder. To view a copy of this licence, visit http://creativecommons.org/licenses/by/4.0/. 


\section{Background}

Nanotechnology is an ever-growing discipline that has seen practical applications in the various fields including medical, pharmaceutical, food, and industrial sectors $[1,2]$. It has been established that metal particles in the nanometer size range (1-100 nm) show discrete physico-chemical properties in comparison to their corresponding bigger size parent metals which is attributed in part to the greater ratio between their surface area and volume [3]. Amongst all the metal nanoparticles that have been synthesized, silver nanoparticles (AgNPs) remain to be the most widely studied and utilized nanoparticles in medical and pharmaceutical industries [4]. Multiple in vitro studies have demonstrated that AgNPs possess significant antimicrobial activity and some of these studies highlighted their potential in overcoming resistance to some bacterial strains $[5,6]$. AgNPs have also displayed a role in anticancer therapy through both induction of apoptosis and targeted drug delivery of antineoplastic agents to the cancer cell site [7, 8]. While the mechanism of bactericidal action and cytotoxicity remains largely unclear, there's enough compelling evidence in the literature to suggest that method of synthesis and reducing agents used to synthesize them plays an important role in ascertaining the level of toxicity and antimicrobial efficacy of AgNPs $[9,10]$.

AgNPs can be synthesized through three different methods, viz., physical, chemical, and biological methods [11]. The former two processes have shown to be more cumbersome and toxic to the environment than the latter. Synthesis by chemical method employs chemicals usage which contributes significantly to the environmental pollution along with a higher energy demand to synthesize the AgNPs [12]. Physical method, in particular evaporation-condensation method, requires a large amount of energy to produce and maintain that increases the cost of synthesis. Henceforth, green synthesis of AgNPs has gained more popularity in the past few years due to the economical and eco-friendly approach associated with it.

Various extracts of plant parts which are rich in secondary plant metabolites have been used for biosynthesis of AgNPs. These natural sources serve the purpose of both a reducing and capping agent, therefore eliminating the need to utilize two separate chemicals to reduce the metal ion and stabilize the nanoparticles, which is often the case in chemical synthesis of AgNPs [13]. Another advantage of biosynthesis of AgNPs using plant extracts or isolated plant constituents is the protective property it imparts to the AgNPs. Uncoated or chemically synthesized AgNPs are reported to induce oxidative stress in organisms, which in turn leads to cytotoxicity followed by cellular apoptosis [14]. Use of antioxidant plant extracts for the biosynthesis of AgNPs has greatly diminished their toxicity [15].

Pomegranate (Punica granatum L.) fruit is rich in polyphenolic phytochemicals which have been shown to exhibit excellent antioxidant properties [16, 17]. Pomegranates are among some of the major crops cultivated in the Sultanate of Oman. They are grown in the region of Jabal Al Akhdar where the temperature is cool and appropriate for optimum growth and development of the plant [18]. Pomegranate peel (PP) is an agro-waste constituting more than half of the weight of the fruit. $\mathrm{PP}$ are abundant sources of vitamins $\left(\mathrm{A}, \mathrm{B}_{6}, \mathrm{~B}_{9}\right.$, and $\left.\mathrm{E}\right)$, potassium, and oxalic acid. Pomegranate peels in Oman are traditionally used in the treatment of intestinal wounds and to aid weight loss. Phytochemical screening of Omani PP extract has revealed the presence of flavonoids and polyphenols, among other chemicals, as the major phytoconstituents [17]. Among the flavonoids and phenolics present in the pomegranate extracts, quercetin and gallic acid (Fig. 1) contribute significantly to their<smiles>O=c1c(O)c(-c2ccc(O)c(O)c2)oc2cc(O)cc(O)c12</smiles>

Quercetin<smiles>O=C(O)c1cc(O)c(O)c(O)c1</smiles>

Gallic acid

Fig. 1 Chemical structures of quercetin and gallic acid 
content [19]. Quercetin is a flavonoid known to exhibit strong angioprotective, anti-inflammatory, and anticancer activity in humans [20]. Gallic acid is a polyphenolic acid having the potential clinical application as an anticancer and apoptosis-inducing agent. Additionally, its anti-inflammatory, antimicrobial, neuroprotective, nephroprotective, and hepatoprotective activities have been well established [21].

In green synthesis of AgNPs, the plant extract has a dual action of being both the reducing agent and the capping agent. Pomegranate peel extracts (PPE) elsewhere have been used for the synthesis of AgNPs and were shown to exhibit good antimicrobial activity [22-24]; however, literature review indicated that AgNPs prepared using Omani PPE have not yet been explored for their antioxidant and cytotoxicity activities.

The current study was designed to synthesize and characterize AgNPs using polyphenolic natural products such as pure quercetin and gallic acid and to compare their bioactivity and physical properties against AgNPs synthesized using PPE. We hypothesize that the AgNPs synthesized by using above three natural reducing agents would differ greatly in their physicochemical properties and thus would show differences in biological activities viz., antimicrobial, cytotoxic, and antioxidant.

\section{Methods}

\subsection{Chemicals, reagents, and microbiological supplies}

Highly pure organic solvents, chemical substances of Sigma such as silver nitrate $\left(\mathrm{AgNO}_{3}\right)$, gallic acid (GA), quercetin (Q), 2,2-diphenyl-1-picrylhydrazyl (DPPH), sodium hydroxide $(\mathrm{NaOH})$, standard antibiotic discs (gentamicin $10 \mu \mathrm{g}$ and cefuroxime $30 \mu \mathrm{g}$ ), and sterile Mueller-Hinton agar (MHA) media plates were procured through the local supplier. Brine shrimp eggs of San Francisco Bay Brand, USA, were used for cytotoxic activity. Bacterial cultures of Staphylococcus aureus, Bacillus subtilis, Escherichia coli, and Proteus vulgaris were obtained from the Biology Department, College of Pharmacy, Sultanate of Oman.

\subsection{Collection and preparation of pomegranate peel extract}

Fresh pomegranate fruits were collected from a farm house in Jabal Al Akhdar (Green mountains) of Addakhliya region in Oman during peak optimum growth season (August-September 2018). The fruits were identified by a faculty member and a voucher specimen was deposited in the Pharmacy lab for the future reference. The fruit was thoroughly washed using distilled water and the seeds were subsequently separated to obtain the peel. The isolated peels were dried under shade at the room temperature for 3 days. The dried peels were ground into uniform coarse powder using a domestic blender.

Approximately $200 \mathrm{~g}$ of pomegranate peel powder upon extraction with ethanol $\left(4-5 \mathrm{~h}, 90{ }^{\circ} \mathrm{C}\right)$ using a soxhlet apparatus yielded a bright red color ethanolic pomegranate peel extract (PPE). The extract was concentrated under reduced pressure $\left(45-50{ }^{\circ} \mathrm{C}\right)$ using a rotary evaporator to obtain the viscous mass (42 g; $21.0 \% \mathrm{w} / \mathrm{w})$. The PPE was stored at $4{ }^{\circ} \mathrm{C}$ in the refrigerator until further use in the experiment.

\subsection{Biosynthesis of AgNPs using PPE, quercetin, and gallic} acid

In a $150-\mathrm{mL}$ beaker containing $50 \mathrm{ml}$ of $2.1 \mathrm{mM}$ $\mathrm{AgNO}_{3}, 2 \mathrm{~mL}$ of freshly prepared PPE $(2.5 \% \mathrm{w} / \mathrm{v}$ in distilled water)/35 ml of $1 \mathrm{mM}$ quercetin (hydroalcoholic solution) $/ 63 \mathrm{~mL}$ of $1 \mathrm{mM}$ gallic acid was added with vigorous stirring at the room temperature. Sufficient quantity of $0.1 \mathrm{M} \mathrm{NaOH}$ solution was added to maintain the $\mathrm{pH}$ at $4-5$. The change in the color of the solution in beaker from pale yellow to deep brown indicated the formation of the AgNPs by PPE/quercetin/gallic acid.

\subsection{Characterization of biosynthesized AgNPs}

The formation of AgNPs was confirmed by measuring the absorbance on a UV-Vis Spectrophotometer (UV Analyst-CT 8200) in the wavelength range of 200-600 $\mathrm{nm}$ and X-ray diffraction (XRD) spectrum measurement using a XRD powder method (MiniFlex 600, Rigaku) as per the standard experimental procedure. The zeta potential of the prepared AgNPs was measured using Zeta Analyzer (NICOMP $\left.{ }^{\mathrm{TM}} 380 \mathrm{ZLS}\right)$ and the average size distribution was measured using Malvern ZetaSizer. Surface morphology, shape of the nanoparticles, and elemental composition of AgNPs were analyzed through field emission scanning electron microscope (FE-SEM; JOEL JSM-7800F) operated at $15 \mathrm{kV}$ with a working distance of $10 \mathrm{~mm}$ and by placing a single drop of aqueous AgNPs on a copper-coated grid for transmission electron microscope (TEM) imaging (JOEL JEM-1400).

\subsection{In vitro antioxidant assay}

Antioxidant activity of the biosynthesized AgNPs was determined using DPPH free radical scavenging assay method. A $0.004 \% \mathrm{w} / \mathrm{v}$ solution of DPPH was prepared by dissolving $2 \mathrm{mg} \mathrm{DPPH}$ in $50 \mathrm{ml}$ of methanol. Three different concentrations of the P-AgNPs, GA-AgNPs, and Q-AgNPs (5, 10, and $20 \mu \mathrm{g} / \mathrm{mL}$ ) were tested for antioxidant activity. Quercetin (0.2, 0.5 , and $1 \mathrm{mM}$ ) was used as a positive control. In separate test tubes, $1 \mathrm{~mL}$ of each concentration of the AgNPs was mixed with $2 \mathrm{~mL}$ of freshly prepared $0.004 \% \mathrm{DPPH}$ solution. Control sample contained methanol in place of AgNPs. The test tubes were 
then left in the dark at room temperature for $1 \mathrm{~h}$ after which their absorbance was measured at $517 \mathrm{~nm}$ [25]. The percentage (\%) inhibition of DPPH radical was calculated as per the following formula;

$$
\text { \%inhibiton of DPPH }=\left[\frac{(A c-A t)}{A t}\right] \times 100
$$

where $\mathrm{Ac}=$ absorbance of the control and At = absorbance of the test sample.

\subsection{Antibacterial activity}

Antimicrobial activity of the biosynthesized AgNPs was measured against two Gram-negative bacteria ( $E$. coli and $P$. vulgaris) and two Gram-positive bacteria ( $S$. aureus and B. subtilis) grown on MHA media. Well diffusion method was used to test the inhibitory effect of three different dilutions of AgNPs against the four bacterial strains. In sterile agar plates, wells were made using a $10-\mathrm{mm}$ cork borer followed by streaking of the plates with bacterial broth. The wells were then filled with 10, 20, and $100 \mu \mathrm{g}$ AgNPs solution. In the control agar plates, wells were loaded with $\mathrm{AgNO}_{3}(1 \mathrm{mM})$, quercetin $(2 \mathrm{mM})$, gallic Acid $(2 \mathrm{mM})$, and pomegranate extract for comparison purpose. Gentamicin $10 \mu \mathrm{g}$ and cefuroxime $30 \mu \mathrm{g}$ antibiotic discs were also added to each plate. The agar plates were incubated at $37^{\circ} \mathrm{C}$ for
$24 \mathrm{~h}$ after which the zone of inhibition around each well was measured [26].

\subsection{In vitro cytotoxicity assay}

Brine shrimp lethality assay method was used to measure the cytotoxic effects of the biosynthesized AgNPs. Brine shrimp eggs were hatched in a glass tank using sea water and an aerator. The larvae were visibly alive and moving towards light source $72 \mathrm{~h}$ after placing in the water and were subsequently used. In three different test tubes, around 10 shrimp larvae were added along with $10-\mathrm{ml}$ sea water. One milliliter of $0.1,0.5$, and $1 \mu \mathrm{g} / \mathrm{mL}$ of all three samples of AgNPs was added to each test tube. A control test tube was prepared by omitting AgNPs. After $24 \mathrm{~h}$, the numbers of dead and alive larvae were counted and percentage mortality was calculated [27].

\subsection{Statistical analysis}

Each experiment was performed in triplicate and the results are expressed as mean $\pm \mathrm{SD}$.

\section{Results}

\subsection{Synthesis and characterization of AgNPs}

The AgNPs were formed immediately upon addition of an alkali solution to the reaction mixture under vigorous stirring. A sharp color change from pale yellow to brown

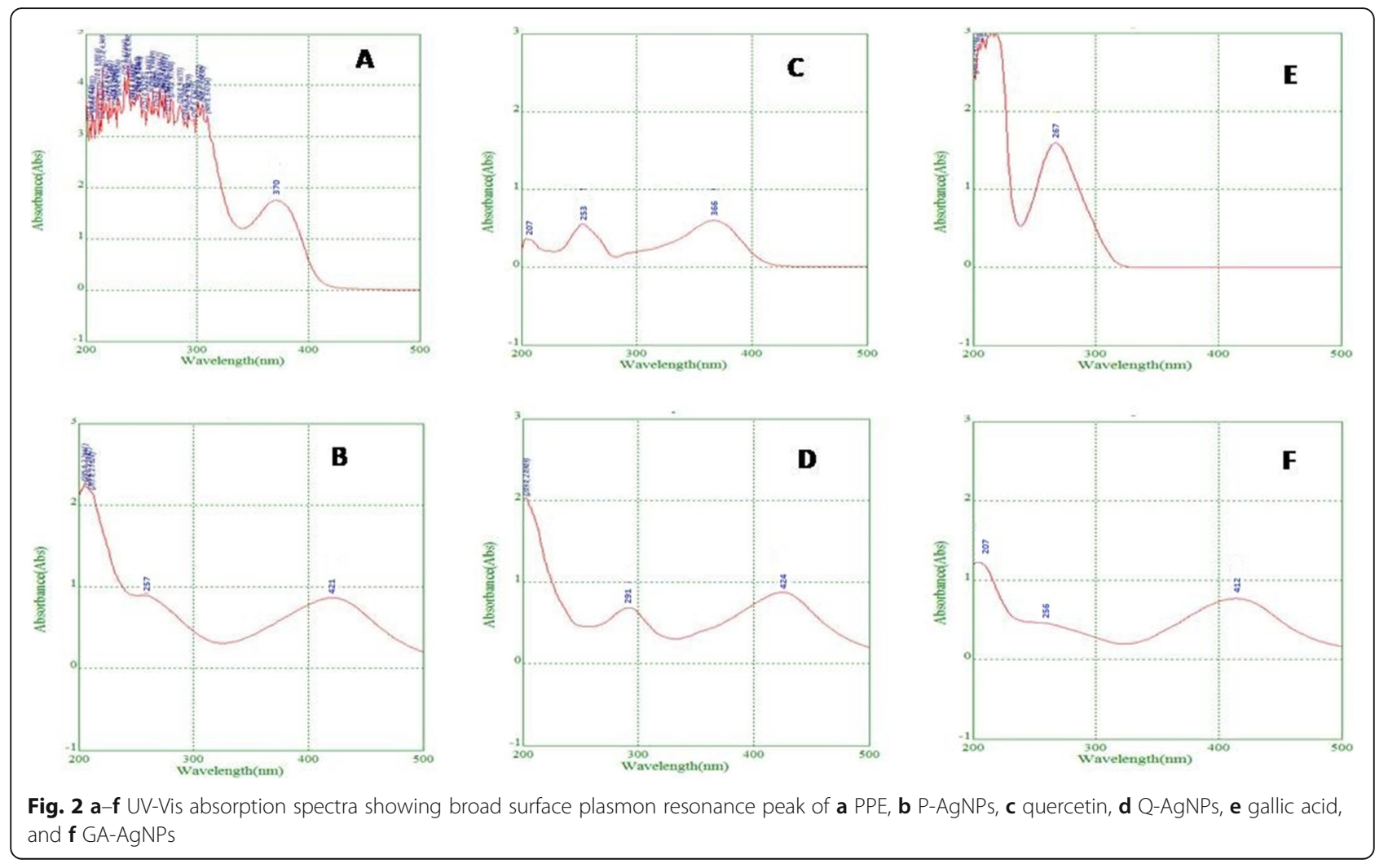


in case of Q-AgNPs and P-AgNPs, and a change from colorless to brown in case of GA-AgNPs indicated the reduction of $\mathrm{AgNO}_{3}$ to form nanoparticles [9]. The formation of eco-friendly AgNPs was confirmed by recording their UV absorption spectrum in the 200-600 $\mathrm{nm}$ range and comparing them with the UV spectrum of PPE, quercetin, and gallic acid. Appearance of new broad surface plasmon resonance peaks at $425 \mathrm{~nm}, 421 \mathrm{~nm}$,
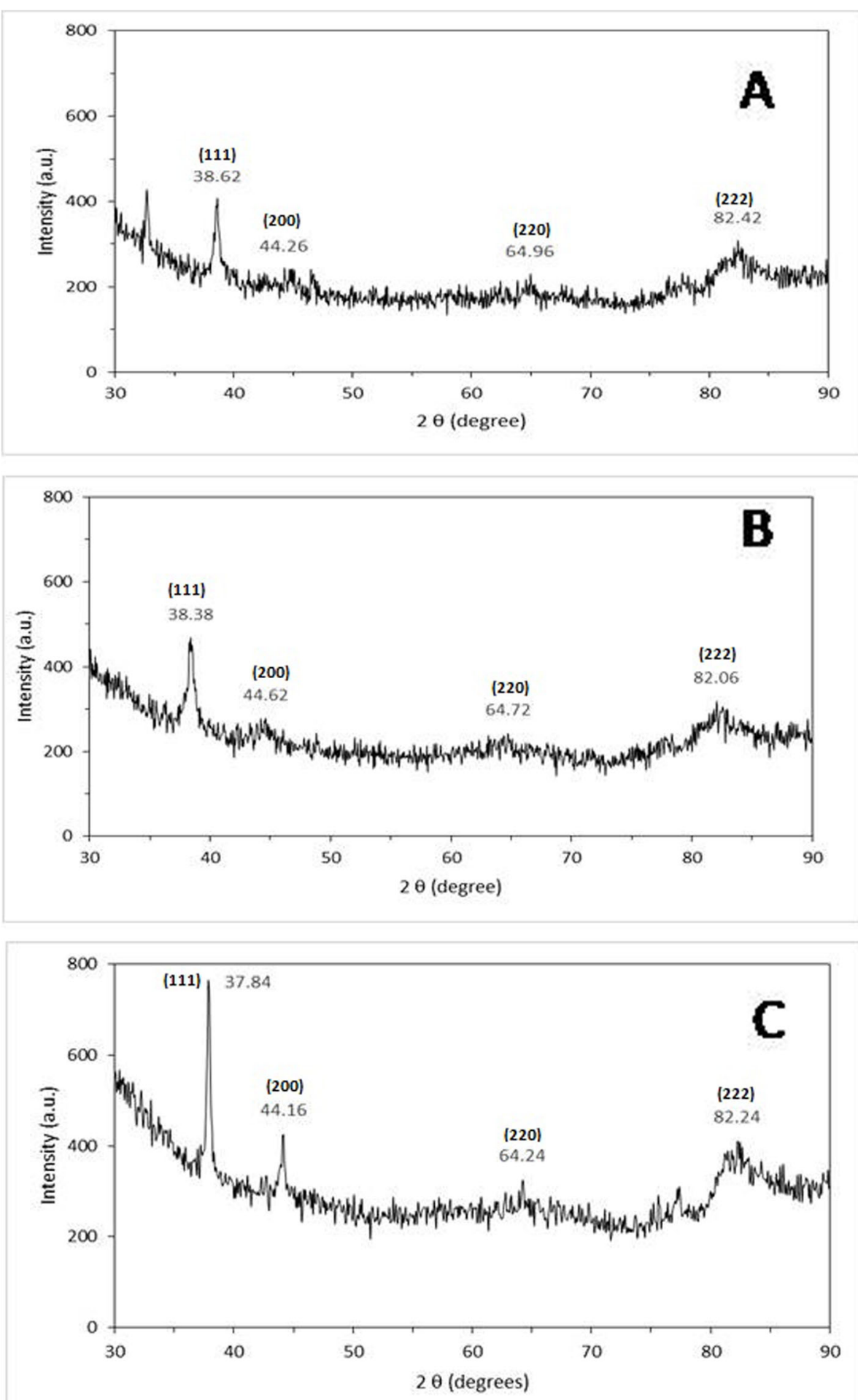

Fig. 3 a-c The XRD pattern of biosynthesized AgNPs. a P-AgNPs. b Q-AgNPs. c GA-AgNPs 
and $413 \mathrm{~nm}$ in the UV-Vis absorption spectra (Fig. 2) for Q-AgNP, P-AgNP, and GA-AgNP, respectively are consistent with the literature data [11, 24].

Four intense peaks in the XRD spectra $(2 \theta=37.84-$ $38.62^{\circ}, 44.16-44.62^{\circ}, 64.16-64.96^{\circ}$, and $82.06-82.42^{\circ}$ ) for all the three samples showed a pattern that matched with the reference cubic silver crystal further confirming formation of AgNPs (Fig. 3) [28]. Furthermore, the crystalline size of P-AgNPs, Q-AgNPs, and GA-AgNPs computed from XRD are noted to be $45.05 \mathrm{~nm}, 25.16 \mathrm{~nm}$, and $32.15 \mathrm{~nm}$, respectively. The values obtained in XRD were matched with JCPDS 4-0783 values for silver. The XRD spectrum for P-AgNPs showed an extra peak around 30 to $35^{\circ}$ which is unaccounted for. This peak could possibly be due to a secondary phase. The high magnification imaging by SEM and TEM showed particles to be predominantly spherical with few aggregates (Figs. 4 and 5). The elemental EDX analysis illustrated high content, strong peaks for the silver. The minor peaks in the spectra may possibly be due to the biomolecules that could have bound to surface of AgNPs.

The average size distribution ( $Z$-average diameter) of the particles was noted to be $43.6 \mathrm{~nm}$ for Q-AgNPs, 31.6 $\mathrm{nm}$ for P-AgNPs, and $21.7 \mathrm{~nm}$ for GA-AgNPs (Fig. 6) with a surface charge of $-18.01 \mathrm{mV},-21.5 \mathrm{mV}$, and $-27.9 \mathrm{mV}$ respectively (Table 1 ).

\subsection{Antimicrobial activity}

P-AgNPs exhibited concentration-dependent good antimicrobial activity against the four bacterial strains. The activity was slightly better against Gram-positive bacteria, in particular B. subtilis, while $P$. vulgaris and $S$. aureus were noted to be resistant at lower concentrations of $10 \mu \mathrm{g}$. However, the antibacterial efficacy of PAgNPs was found to be significantly lower than the PPE. GA-AgNPs showed bacterial growth inhibition comparable to that of P-AgNPs, but with a slightly more pronounced effect against E. coli. Q-AgNPs showed the antimicrobial activity only at $100 \mu \mathrm{g}$. P. vulgaris was noted to be resistant to the AgNPs at all the three tested concentrations (Table 2).

\subsection{In vitro antioxidant assay}

The results of in vitro inhibition of DPPH free radicals by the biosynthesized AgNPs are presented in Table 3. P-AgNPs exhibited excellent antioxidant properties (84.85-89.20\%) followed by Q-AgNPs (66.95-84.32\%) and are comparable to positive control quercetin (92.74-95.32\%). GA-AgNPs showed a moderate inhibition of DPPH radicals and thus lower antioxidant activity (52.06-63.28\%). The DPPH radical scavenging activity of AgNPs at $20 \mu \mathrm{g} / \mathrm{mL}$ was found in the following order: P-AgNPs $>$ Q-AgNPs $>$ GA-AgNPs.

\subsection{In vitro cytotoxic activity}

The results of Brine shrimp lethality assay of the AgNPs indicated that P-AgNPs caused 100\% mortality of the larvae at $1 \mu \mathrm{g} / \mathrm{mL}$ and are highly cytotoxic. The GAAgNPs and Q-AgNPs showed 89.2 and $88.5 \%$ mortality respectively (Table 4).

\section{Discussion}

Formation of silver nanoparticles was confirmed through the observed color change and based on the shift in the $\lambda_{\max }$ of the peaks in the UV spectrum. Size and charge of the AgNPs varied depending on the reducing agent used. The size and charge of AgNPs synthesized using PPE falls somewhat in between the ones synthesized using quercetin and gallic acid. Contrary to our results, Joshi et al., in 2018, reported much lower zeta potential of $-68.93 \mathrm{mV}$ and a much larger average particle size distribution (57.7$142.4 \mathrm{~nm}$ ) for the AgNPs synthesized using PPE [28]. However, the average particle size of $36 \mathrm{~nm}$ and zeta potential $(-24.1 \mathrm{mV})$ of AgNPs biosynthesized by Jyoti et al., using aqueous leaves extract of Urtica dioica (Linn.), are consistent with the results obtained for P-AgNPs in our study [29]. The variation in the
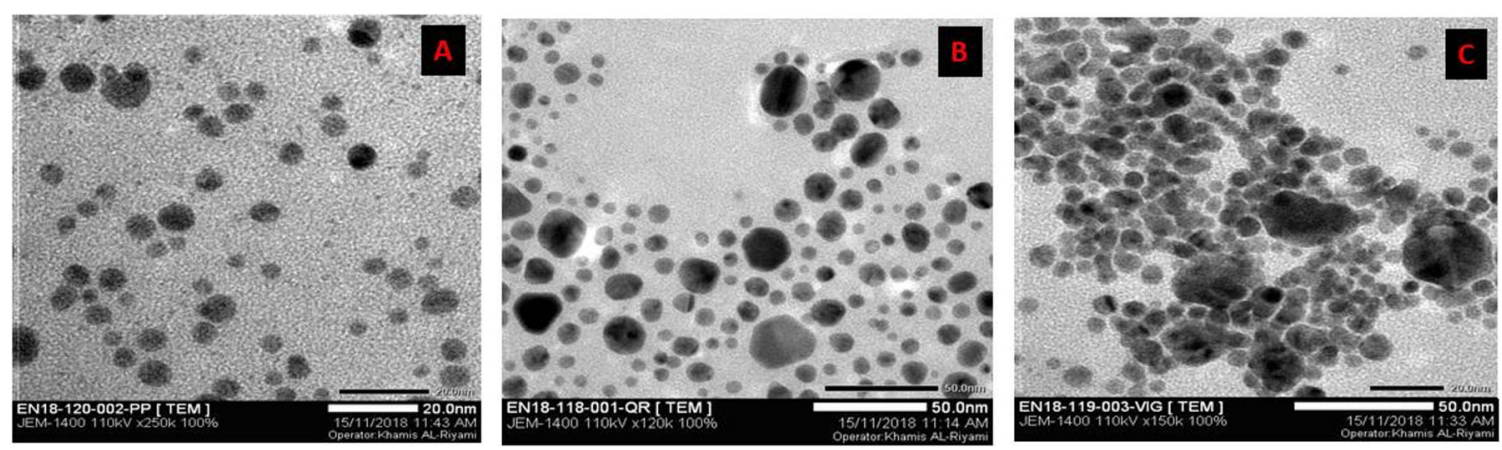

Fig. 4 a-c. TEM analysis of biosynthesized AgNPs. a P-AgNPs. b Q-AgNPs. c GA-AgNPs 

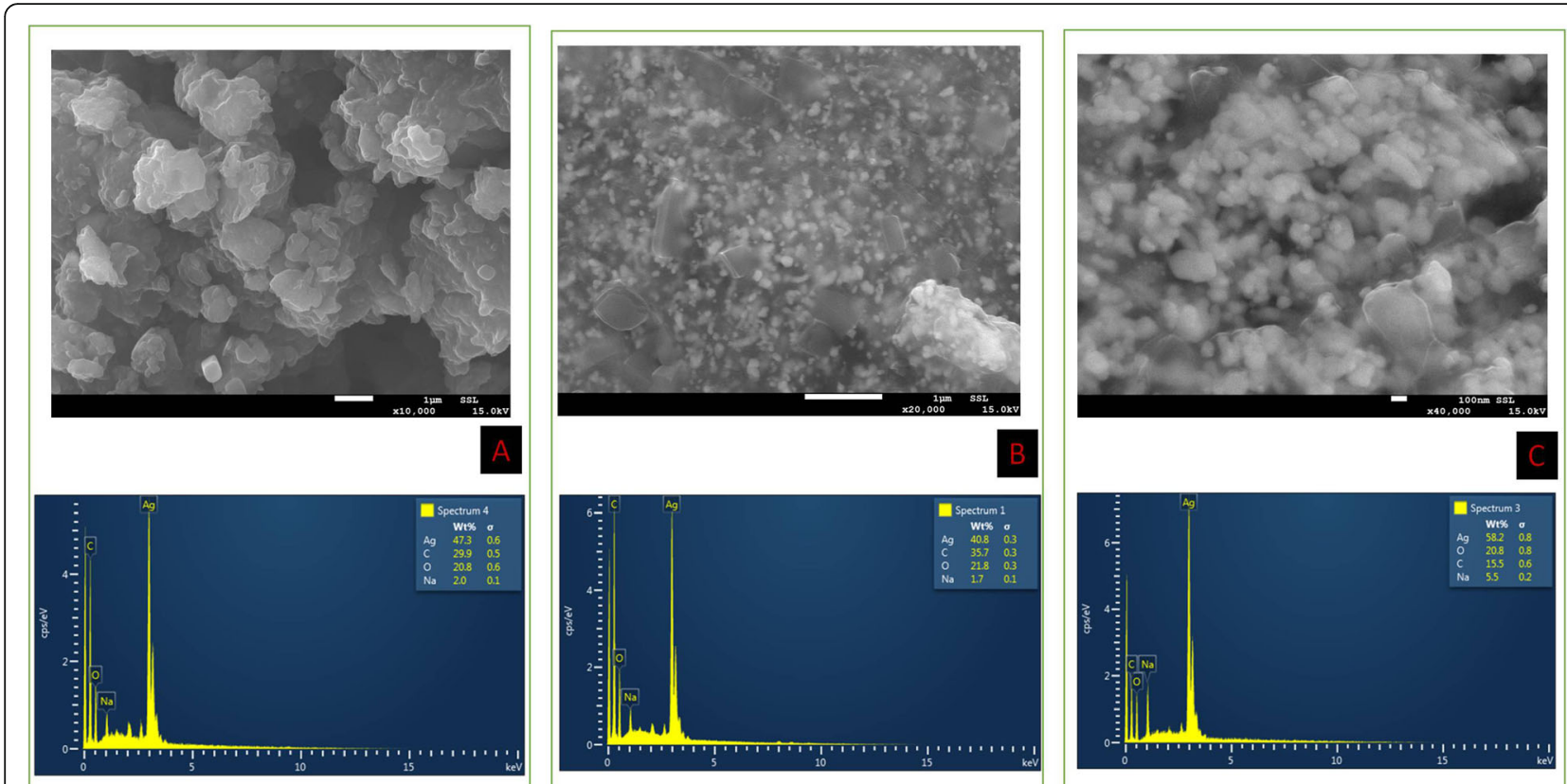

Fig. 5 a-c. Microphotographs showing surface characteristics and composition of biosynthesized AgNPs by FE-SEM-EDX analysis. a P-AgNPs. b QAgNPs. c GA-AgNPs

size of three AgNPs could be due to the difference in the nature of reducing agents and chemical composition of PPE with respect to pure natural products, gallic acid and quercetin. The zeta potential values indicate good stability of AgNPs which could be attributed to the natural bioactive compounds responsible for capping, reduction of silver ions, and stability of nanoparticles.

Antimicrobial activity of P-AgNPs compared to PPE was lower than expected. This could be due to the
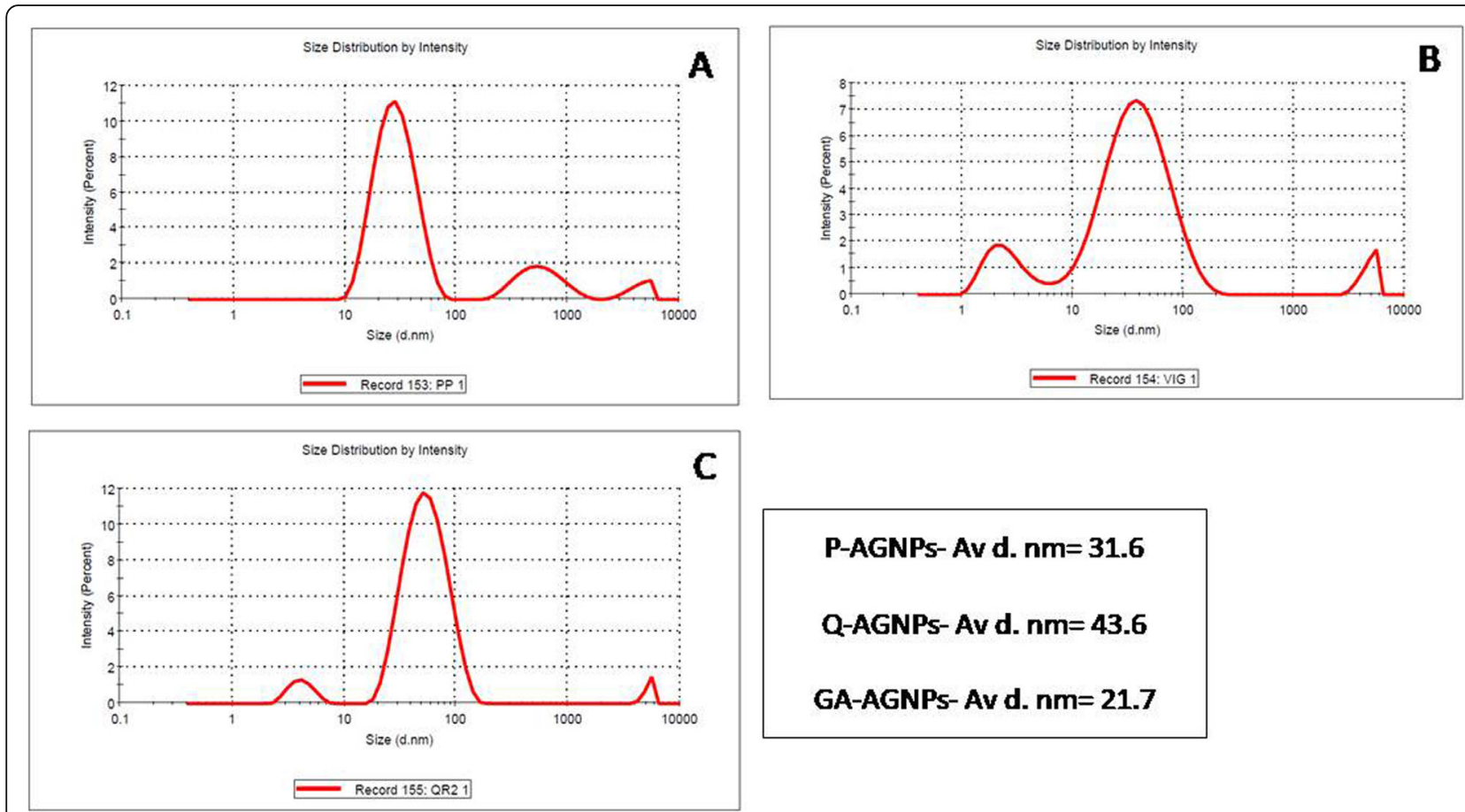

P-AGNPs- Av d. $\mathrm{nm}=\mathbf{3 1 . 6}$

Q-AGNPs- Av d. $n m=43.6$

GA-AGNPs-Av d. $\mathrm{nm}=\mathbf{2 1 . 7}$

Fig. 6 a-c The average particle size distribution of biosynthesized AgNPs. a P-AgNPs. b Q-AgNPs. c GA-AgNPs 
Table 1 Zeta potential and average size distribution of ecofriendly biosynthesized AgNPs

\begin{tabular}{lll}
\hline & Average sizedistribution $(\mathbf{n m})$ & Zeta potential $(\mathbf{m V})$ \\
\hline Q-AgNPs & 43.6 & -18.01 \\
P-AgNPs & 31.6 & -21.5 \\
GA-AgNPs & 21.7 & -27.9 \\
\hline
\end{tabular}

presence of other bioactive phytoconstituents in the PPE which would have exerted an additive effect against microbial growth. The presence of a negative surface charge on the nanoparticles which correspond closely to the charge of the bacterial cell wall could have also been a driving factor in decreased efficacy through repulsion and subsequent decreased uptake by the bacteria [30]. The slightly more pronounced inhibitory effect of GAAgNPs against E. coli could be attributed to their relatively thin cell walls that might have facilitated the entry of the GA-AgNPs [31]. This result is of quite significance as GA solution did not inhibit bacterial growth. Q-AgNPs antimicrobial activity at higher concentration can be attributed to their large particle size which prevents their penetration of the bacterial cell wall.

The antibacterial results of our study are in agreement with the result obtained in a previous study [32] (Table 2). The AgNPs have been reported to exert bactericidal activity by multiple mechanisms of action such as by attacking the respiratory chain and cell division leading to cell death, alteration of cell membrane permeability, release of polysaccharides, and membrane potential [33]. Various studies have shown that a negative charge imparted on

Table 2 Antibacterial activity of biosynthesized AgNPs

\begin{tabular}{llllll}
\hline Sample & Concentration & \multicolumn{5}{l}{ Zone of inhibition $(\mathbf{m m})$} \\
\cline { 3 - 6 } & & S. aureus & B. subtilis & E. coli & P. vulgaris \\
\hline Q-AgNPs & $100 \mu \mathrm{g}$ & 11.7 & 14 & 12.4 & - \\
& $20 \mu \mathrm{g}$ & - & - & - & - \\
& $10 \mu \mathrm{g}$ & - & - & - & - \\
P-AgNPs & $100 \mu \mathrm{g}$ & 15 & 15.2 & 15.2 & 14.7 \\
& $20 \mu \mathrm{g}$ & 14.2 & 14 & 13.2 & - \\
& $10 \mu \mathrm{g}$ & - & 13.2 & 12.6 & - \\
GA-AgNPs & $100 \mu \mathrm{g}$ & 15.2 & 14.7 & 17.7 & 14.7 \\
& $20 \mu \mathrm{g}$ & - & 13.9 & - & - \\
& $10 \mu \mathrm{g}$ & - & - & - & - \\
AgNO & $2 \mathrm{mM}$ & 20 & 20 & 19 & 13.2 \\
Quercetin & $1 \mathrm{mM}$ & 12.2 & 15 & - & - \\
Gallic Acid & $1 \mathrm{mM}$ & - & - & - & - \\
PPE & $2.1 \% \mathrm{~W} / \mathrm{v}$ & 23 & 22 & 21.8 & 17.8 \\
Gentamicin & $10 \mu \mathrm{g}$ & 24.4 & 35 & 24.9 & 24.3 \\
Cefuroxime & $30 \mu \mathrm{gg}$ & 19.3 & - & 12.2 & 19.3 \\
\hline
\end{tabular}

Table 3 In vitro antioxidant activity of biosynthesized AgNPs against DPPH free radicals

\begin{tabular}{llll}
\hline & \multicolumn{2}{l}{$\%$ inhibition of DPPH (mean \pm SD) } \\
\cline { 2 - 4 } & $\mathbf{2 0} \boldsymbol{\mu g} / \mathbf{m L}$ & $\mathbf{1 0} \boldsymbol{\mu g} / \mathbf{m L}$ & $\mathbf{5} \boldsymbol{\mu g} / \mathbf{m L}$ \\
\hline Q-AgNPs & $84.32 \pm 1.19$ & $83.93 \pm 1.95$ & $66.95 \pm 1.61$ \\
P-AgNPs & $89.20 \pm 0.31$ & $85.90 \pm 0.88$ & $84.85 \pm 0.88$ \\
GA-AgNPs & $63.28 \pm 2.67$ & $61.07 \pm 1.83$ & $52.06 \pm 0.61$ \\
Quercetin & $95.32 \pm 1.3$ & $93.43 \pm 0.76$ & $92.74 \pm 0.94$ \\
& $(1 \mathrm{mM})$ & $(0.5 \mathrm{mM})$ & $(0.2 \mathrm{mM})$ \\
\hline
\end{tabular}

AgNPs can significantly exhibit cytotoxicity [30, 34]. Sizedependent toxicity has been shown to be more prominent in particles less than $50 \mathrm{~nm}$. Smaller particles can penetrate through the cell membrane at a much larger extent owing to the greater surface area, leading to more interaction with the membrane.

Antioxidant activity results of the present study are in agreement with previously published reports demonstrating beneficial effects of AgNPs in combating oxidative stress [35]. The higher activity demonstrated by PAgNPs could again be due to the presence of unreacted bioactive phytoconstituents present in PPE.

\section{Conclusion}

The present study demonstrates a simple, one pot, ecofriendly biosynthesis of AgNPs using Omani pomegranate peel extract and two of its polyphenolic constituents, namely quercetin and gallic acid as reducing agents. The phytochemicals (flavonoids, alkaloids, glycosides, terpenoids) present in the pomegranate peel extract acted as better reducing and capping agents in comparison to the pure quercetin and gallic acid for the formation of stable AgNPs. A peak in the UV spectrum at $421 \mathrm{~nm}$ and in the XRD at $2 \theta=38.62,44.26,64.96$, and 82.42 confirmed the formation of P-AgNPs. Further characterization by SEM and TEM analysis showed particles to be predominantly spherical with few aggregates, an average size distribution of $31.6 \mathrm{~nm}$ and a surface charge of $-21.5 \mathrm{mV}$. Beside physicochemical advantages of P-AgNPs over Q-AgNPs and GA-AgNPs, these have shown improved antibacterial, antioxidant (84.85-89.20\% inhibition of DPPH over 5 to $20 \mu \mathrm{g} / \mathrm{mL}$ ) and promising cytotoxic properties (100\% mortality) in

Table $\mathbf{4}$ In vitro cytotoxic activity of biosynthesized AgNPs in Brine shrimp lethality test

\begin{tabular}{|c|c|c|c|}
\hline & \multicolumn{3}{|c|}{$\%$ Mortality } \\
\hline & $1 \mu \mathrm{g} / \mathrm{mL}$ & $0.5 \mu \mathrm{g} / \mathrm{mL}$ & $0.1 \mu \mathrm{g} / \mathrm{mL}$ \\
\hline Q-AgNPs & $88.5 \pm 2.7$ & $78.2 \pm 3.9$ & $56.7 \pm 2.4$ \\
\hline P-AgNPs & 100 & $93.6 \pm 4.5$ & $77.3 \pm 5.2$ \\
\hline GA-AgNPs & $89.2 \pm 3.4$ & $83.6 \pm 3.1$ & $67.6 \pm 2.8$ \\
\hline
\end{tabular}


Brine shrimp lethality assay. The other advantages of using peel extract for the biosynthesis include cost effectiveness as pomegranate peels are agro-waste, energy efficient, and their ability to protect the environment leading to lesser waste and safer products. The biosynthesized AgNPs using pomegranate peel therefore seems to offer viable alternative to chemical synthesis. However, further studies are required to ascertain the benefits of P-AgNPs over traditional AgNPs.

\begin{abstract}
Abbreviations
AgNPs: Silver nanoparticles; $\mathrm{AgNO}_{3}$ : Silver nitrate; GA: Gallic acid; Q: Quercetin; DPPH: 2,2-Diphenyl-1-picrylhydrazyl; $\mathrm{NaOH}$ : Sodium hydroxide: MHA: Mueller-hinton agar; PPE: Pomegranate peel extract; XRD: X-ray diffraction; FE-SEM: Field emission scanning electron microscope; TEM: Transmission electron microscope; GA: Gallic acid; PAgNPs: Pomegranate-coated silver nanoparticles; GA-AgNPs: Gallic acidcoated silver nanoparticles; Q-AgNPs: Quercetin-coated silver nanoparticles; EDX: Energy dispersive $\mathrm{X}$-ray analysis
\end{abstract}

\section{Acknowledgements}

Authors would like to thank Dr. Htet Htet Kyaw of SQU, Oman; Dr. Farhan Jalees of Jamia Hamdard University, India; and Dr. Khamis Al Riyami of UoN, Oman, for their help and support in analysis of silver nanoparticles by XRD, TEM, and SEM techniques.

\section{Authors' contributions}

PG: Planning, experiment performance, writing the manuscript. RC: Planning, experiment performance, writing the manuscript. VR: Planning, experiment performance, writing the manuscript. IA: Analysis of data, reviewing, and editing of MS. SK: Supervised the experiment, performed major corrections in the experiment, reviewed and edited the manuscript. All authors read and approved the final manuscript.

\section{Funding}

None

Availability of data and materials

Not applicable

\section{Declarations}

Ethics approval and consent to participate

Not applicable

\section{Consent for publication}

Not applicable

\section{Competing interests}

Authors declare no conflict of interest.

\section{Author details}

${ }^{1}$ College of Pharmacy, National University of Science and Technology, PO Box no 620, PC 130 Muscat, Sultanate of Oman. ${ }^{2}$ College of Arts and Sciences, University of Nizwa, Birkat Al Mouz, Nizwa, Sultanate of Oman.

Received: 3 November 2020 Accepted: 7 April 2021

Published online: 26 April 2021

\section{References}

1. Haris M, Kumar A, Ahmad A, Abuzinadah MF, Basheikh M, Khan SA, Mujeeb M (2017) Microwave-assisted green synthesis and antimicrobial activity of silver nanoparticles derived from supercritical carbon dioxide extract of the fresh aerial parts of Phyllanthus niruri L. Tropical J Pharm Res 16(12):29672976

2. Khatoon N, Ahmed MJ, Sardar M (2017) Biotechnological applications of green synthesized silver nanoparticles. J Nanoscie Curr Res 2(1):107

3. Mody W, Siwale R, Singh A, Mody HR (2010) Introduction to metallic nanoparticles. J Pharm Bioallied Sci 2(4):282-289
4. Tran Q, Nguyen V, Le A (2013) Silver nanoparticles: synthesis, properties, toxicology, applications and perspectives. Adv Nat Sci Nanosci Nanotechnol 4(3):033001

5. Singh M, Singh S, Prasad S, Gambhir I (2008) Nanotechnology in medicine and antibacterial effect of silver nanoparticles. Dig J Nanomater Bios 3(3): $115-122$

6. Lara H, Ayala-Núñez N, IxtepanTurrent L, Rodríguez Padilla C (2009) Bactericidal effect of silver nanoparticles against multidrug-resistant bacteria. World J Microb Biot 26(4):615-621

7. Castro-Aceituno V, Ahn S, Simu SY, Singh P, Mathiyalagan R, Lee HA, Yang DC (2016) Anticancer activity of silver nanoparticles from Panax ginseng fresh leaves in human cancer cells. Biomed Pharmacother 84:158-165

8. Wang X, Yang L, Chen Z, Shin DM (2008) Application of nanotechnology in cancer therapy and imaging. CA Cancer J Clin 58:97-110

9. Logeswari P, Silambarasan S, Abraham J (2013) Eco-friendly synthesis of silver nanoparticles from commercially available plant powders and their antibacterial properties. Sci Iran 20(3):1049-1054

10. Logeswari P, Silambarasan S, Abraham J (2015) Synthesis of silver nanoparticles using plants extract and analysis of their antimicrobial property. J Saudi Chem Soc 19(3):311-317

11. Iravani S, Korbekandi H, Mirmohammadi SV, Zolfaghari B (2014) Synthesis of silver nanoparticles: chemical, physical and biological methods. Res Pharm Sci 9(6):385-406

12. Gudikandula K, Maringanti SC (2016) Synthesis of silver nanoparticles by chemical and biological methods and their antimicrobial properties. J Exp Nanosci 11(9):714-721

13. Makarov W, Love AJ, Sinitsyna OV, Makarova SS, Yaminsky IV, Taliansky ME, Kalinina NO (2014) "Green" nanotechnologies: Synthesis of metal nanoparticles using plants. Acta Naturae 6(1):35-44

14. Nguyen K, Seligy V, Massarsky A, Moon T, Rippstein P, Tan J, Tabyabali AF (2013) Comparison of toxicity of uncoated and coated silver nanoparticles. J Phy Conf Ser 429:012025

15. Bhakya S, Muthukrishnan S, Sukumaran M, Muthukumar M (2015) Biogenic synthesis of silver nanoparticles and their antioxidant and antibacterial activity. Appl Nanosci 6(5):755-766

16. Al-Musharfi NK, Al-Wahaibi HS, Khan SA (2015) Comparison of ascorbic acid, total phenolic content and antioxidant activities of fresh juices of six fruits grown in Oman. J Food Process Technol 6:11

17. Al-Rawahi A, Edwards G, Al-Sibani M, Al-Thani G, Al-Harrasi A, Shafiur Rahman M (2014) Phenolic constituents of Pomegranate peels (Punica granatum L.) cultivated in Oman. EJMP 4(3):315-331

18. Al-Said F, Opara L, Al-Yahyai R (2009) Physico-chemical and textural quality attributes of pomegranate cultivars (Punica granatum L.) grown in the Sultanate of Oman. J Food Eng 90(1):129-134

19. Orak H, Yagar H, Isbilir S (2012) Comparison of antioxidant activities of juice, peel, and seed of pomegranate (Punica granatum L) and inter-relationships with total phenolic, tannin, anthocyanin, and flavonoid contents. Food Sci Biotechno 21(2):373-387

20. D'Andrea D (2015) Quercetin: A flavonol with multifaceted therapeutic applications? Fitoterapia 106:256-271

21. Badhani B, Sharma N, Kakkar R (2015) Gallic acid: A versatile antioxidant with promising therapeutic and industrial applications. RSC Adv 5:27540-27557

22. Akkiraju P, Tathe P, Mamillapalli S (2017) Green synthesis of silver nanoparticles from Punica granatum L. and its antimicrobial activity. Adv Appl Sci Res 8(1):42-49

23. Shanmugavadivu M, Kuppusamy S, Ranjithkumar R (2014) Synthesis of Pomegranate peel extract mediated silver nanoparticles and its antibacterial activity. Am J Adv Drug Deliv 2(2):174-182

24. Oraibi A, Mohsien R, Atea W, Yahia H, Raheem L (2016) Antibacterial activity of silver nanoparticles and Pomegranate (Punica granatum L.) extracts. Int J Curr Microbiol Appl Sci 5(12):131-140

25. Al-Breiki AM, Al-Brashdi HM, Al-Sabahi JN, Khan SA (2018) Comparative GCMS analysis, in-vitro antioxidant and antimicrobial activities of the essential oils isolated from the peel of Omani lime. Chiang Mai J Sci 45(4):1782-1795

26. Alsaraf S, Hadi Z, Al-Lawati WM, Al Lawati AA, Khan SA (2020) Chemical composition, in vitro antibacterial and antioxidant potential of Omani Thyme essential oil along with in silico studies of its major constituent. J King Saud Univ Sci 32(1):1021-1028

27. Abdelrahman MH, Hussain RO, Shaheed DS, AbuKhader M, Khan SA (2019) GC-MS analysis and in vitro biological studies on fixed oil isolated from the waste pits of two varieties of Olea europaea L. OCL 26:28 
28. Joshi SJ, Geetha SJ, Al-Mamari S, Al-Azkawi A (2018) Green synthesis of silver nanoparticles using pomegranate peel extracts and its application in photocatalytic degradation of methylene blue. Jundishpur J Nat Pharm Prod 13:e67846

29. Jyoti K, Baunthiyal M, Singh A (2016) Characterization of silver nanoparticles synthesized using Urtica dioica Linn. leaves and their synergistic effects with antibiotics. J Rad Res Appl Sci 9:217-227

30. Silva T, Pokhrel L, Dubey B, Tolaymat T, Maier K, Liu X (2014) Particle size, surface charge and concentration dependent ecotoxicity of three organocoated silver nanoparticles: Comparison between general linear modelpredicted and observed toxicity. Sci Total Environ 468-469:968-976

31. Christian P, Von der Kammer F, Baalousha M, Hofmann T (2008) Nanoparticles: structure, properties, preparation and behaviour in environmental media. Ecotoxicol 17(5):326-343

32. Vanaraj S, Keerthana B, Preethi K (2017) Biosynthesis, characterization of silver nanoparticles using quercetin from Clitoria ternatea $L$ to enhance toxicity against bacterial biofilm. J Inorg Organomet Polym 27(5):1412-1422

33. Abdel-Aziz MS, Shaheen MS, El-Nekeety AA, Abdel-Wahhab MA (2014) Antioxidant and antibacterial activity of silver nanoparticles biosynthesized using Chenopodium murale leaf extract. I Saudi Chem Soc 18:356-363

34. Shin S, Song I, Um S (2015) Role of physicochemical properties in nanoparticle toxicity. Nanomaterials 5(3):1351-1365

35. Kumar B, Debut A, Smita K, Cumbal L (2016) Extracellular green synthesis of silver nanoparticles using Amazonian fruit Araza (Eugenia stipitata McVaugh). Trans Nonferrous Metals Soc China 26:2363-2371

\section{Publisher's Note}

Springer Nature remains neutral with regard to jurisdictional claims in published maps and institutional affiliations.

\section{Submit your manuscript to a SpringerOpen ${ }^{\circ}$ journal and benefit from:}

- Convenient online submission

- Rigorous peer review

- Open access: articles freely available online

High visibility within the field

- Retaining the copyright to your article

Submit your next manuscript at $\boldsymbol{\nabla}$ springeropen.com 